\title{
Effective Short-Term Energy Accumulation for Means of Transport
}

\author{
J. Plomer* \\ Faculty of Transportation Sciences, Czech Technical University, Prague, Czech Republic \\ *Corresponding author: Jan.Plomer@seznam.cz
}

DOI: 10.2478/trans-2014-0005

\begin{abstract}
This paper presents a new conceptual design of an efficient flywheel battery, designed from commercially available components. The basic idea is based on a possibility of using a spare wheel of a vehicle, or its steel or aluminium disc, as the gyroscope rotor at an early stage of rotor development. Even low rotation speeds accumulate sufficient amount of energy to accelerate a small vehicle in a city.
\end{abstract}

KEY WORDS: Flywheel battery, gyrobus, energy recuperation.

\section{INTRODUCTION}

For centuries, flywheels have been used in smooth running rotated mechanisms. Heavy rotation stone wheels served as flywheels in original purely mechanical powertrains. The Potter's wheel represents one of the ancient flywheels in the steam century, flywheels helped to overcome the dead body of a crank mechanism of steam engines by exploiting the stored kinetic energy. The flywheel currently forms an integral part of any combustion engine, in which it balances uneven rotations of the engine.

Unlike the initial very simple structures, flywheels have nowadays much more advanced designs to allow more complex functions (Lee et al., 2011; Plomer, 2010; Plomer, 2011; Yang, 2012). Thanks to that, flywheels are currently employed as short-term energy accumulators, whose energy can be reused later. In the future, applications are extensive and could include, e.g. hybrid and electric vehicles (Plomer, 2013), or voltage stabilization in electric distribution networks. The shape and design of the flywheel are optimized to store as much energy as possible. Materials from which the flywheels are constructed, e.g. as a combination of a heavy flywheel kernel and hardening of carbon fiber on the perimeter, are suitable even for very high-speed flywheels. In high-speed flywheels, a large amount of energy can be stored in a relatively low-weight flywheel. The importance of low-weight flywheels increases, especially for mobile applications including engines in vehicles.

In the past, the flywheel had been used as a source of energy for gyrobus drives, e.g. in Switzerland, Belgium, Congo, Sweden and China. A Swiss company Maschinenfabrik Oerlikon (ABB today) had 19 such gyrobuses in total. The gyrobus was connected to the supply of 500 Volts at each stop through three collectors placed on the roof of the vehicle. During the time necessary for changing passengers, the current from the power grid increased the speed of the flywheel through a three-phase asynchronous engine with a short anchor. The amount of energy accumulated in the flywheel was sufficient to cover a distance of several kilometers to a next stop, with an additional power supply pole. Moreover, during the acceleration of the gyrobus, the flywheel supplied the electric energy to the asynchronous 
traction engine. In case of sufficient slowdown of the gyrobus, the traction electric engine worked as a generator mode and supplied the energy back into the flywheel. This means that already at that time a part of braking energy was recovered.

On the other hand, due to the action of the gyroscope torque, the axes of rotation of heavy flywheels had to be vertical to minimize effects on driving properties of the vehicles. This often led to inconvenient designs of buses because the flywheel with an asynchronous motor was placed in the middle of the vehicle, which restricted a space for passengers.

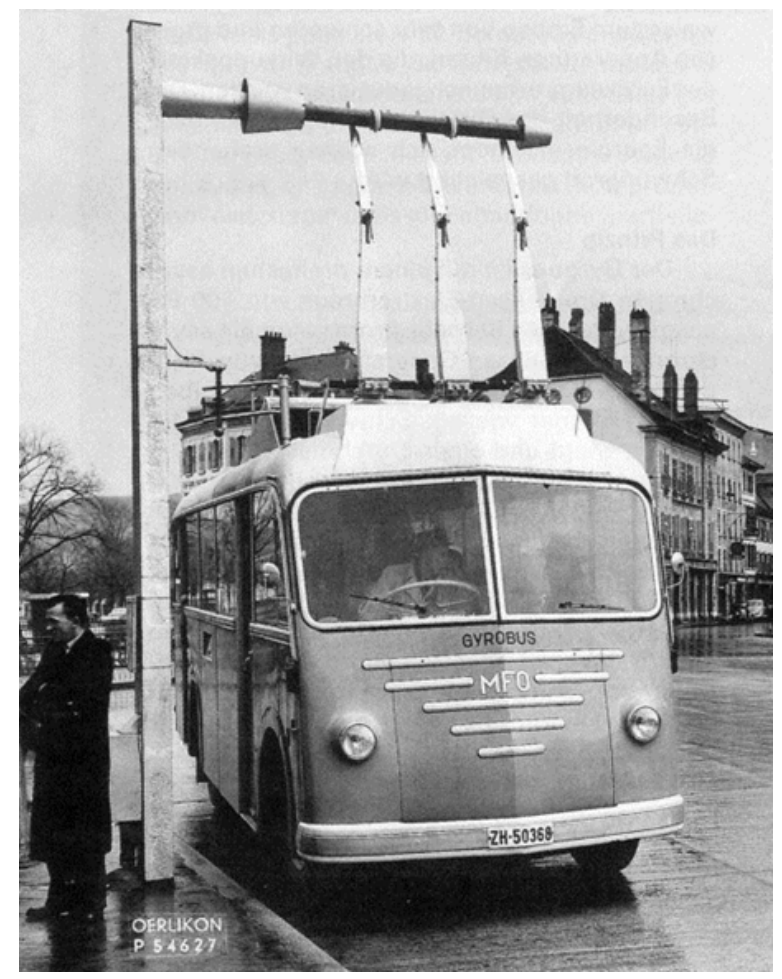

Figure 1: Swiss gyrobus.

The revolutionary drive of the city transport vehicles mentioned above had several advantages over other means of public transportation. The first and foremost advantage was a zeroemission operation, because there was no internal combustion engine in the vehicle at all. Moreover, the vehicle in operation was substantially quieter. Another advantage was no need to build and maintain overhead contact lines between individual stops.

However, the design of the gyrobus from the 1950s had several disadvantages, in particular those stemming from a limited amount of materials that could be used for the design of the flywheel. Since a steel flywheel was used in the gyrobus, the maximum rotation speed was significantly limited and the requirement for a sufficient amount of energy storage was ensured by adequately large mass of the flywheel. Therefore, a total weight of the gyrobus increased significantly by the heavy flywheel and related safety demands were increased. Despite of limitation of the maximum flywheel speed - approximately at $30001 / \mathrm{min}$, a flywheel embedding was crucial due to its large mass. The flywheel was placed at a special chamber with decreased air pressure to reduce friction losses. The worse handling characteristics due to the higher weight and the gyroscope torque had negative effects on the turning ability, which represented another disadvantage of the gyrobus in comparison with diesel-powered busses. 


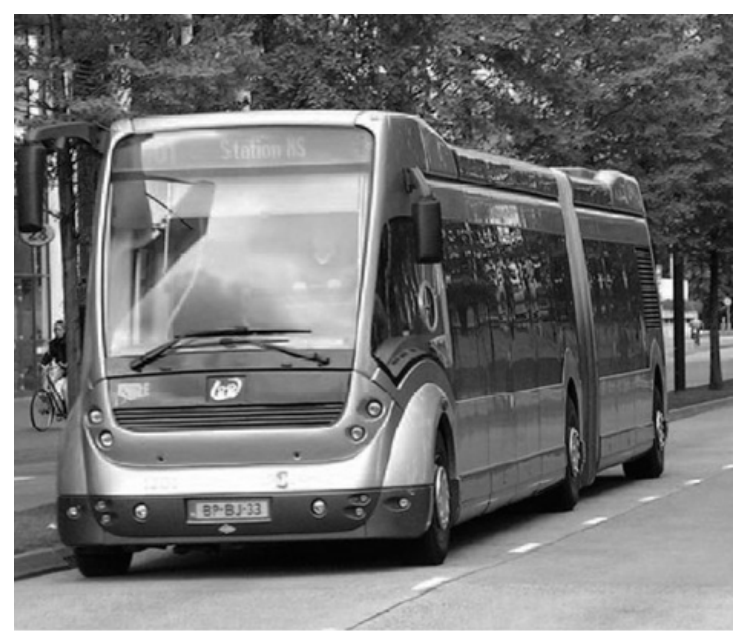

Figure 2: APTS Phileas.

Gyrobuses from the 1950s have not spread due to many imperfections and their production was terminated. However, the idea of an easy usage of flywheel kinetic energy is alive and attracts current designers. A hybrid bus APTS Phileas from 2004 (Figure 2) can be mentioned as an example. This low-floor three-car bus combines an internal combustion engine, electric engine and flywheel of a power of $300 \mathrm{~kW}$ facilitating to store energy up to $4 \mathrm{kWh}$. The flywheel accumulates the energy derived exclusively from braking recovery. The accumulated energy can be used to drive the vehicle for a distance of approximately $3 \mathrm{~km}$ and the fuel saving of this hybrid system in comparison with conventional drives reaches up to $30 \%$. Up to about $10 \%$ of this fuel saving is attributed to the flywheel itself. This paper aims to present a new design of a flywheel battery based on common components of vehicles, which allows effective accumulating of energy for later re-use for vehicle acceleration.

\section{THE EXISTING APPLICATIONS OF FLYWHEEL BATTERY}

Increasing demands on technical parameters of powertrains and, at the same time, needs to reduce energy consumption and contemporary re-usage of energy from renewable sources, have led to inventions of new technologies of flywheel batteries and their applications into new fields. In addition to the stationary flywheel batteries, mobile applications play an important role nowadays, e.g. in transportation. Mobility requirements have led to flywheel miniaturization in terms of its volume and weight.

Some examples are shown as follows:

- Small flywheel systems for short-term voltage balancing in the power grid. These systems have relatively small specific density, since the volume and weight are limited. On the other hand, a high specific output power can be achieved.

- Usage of the flywheel to balance the peak voltage of electric vehicles. The aim is to reduce significantly high currents from the original battery power for the traction engine. The battery life is significantly prolonged by reducing the peak current.

- Wind-diesel generator with flywheel battery. At the beginning of the 21st century, the wind-diesel power station with a kinetic energy accumulator was designed. Diesel generator and flywheel compensate wind oscillations. Thanks to the flywheel implementation, the wind unit is able to deliver high power within a period of almost 2 minutes. 
- Flywheel for photovoltaic systems. Incorporating flywheels into a photovoltaic system, the extension of the energy supply up to approximately 30\% can be achieved.

- Flywheel in the power grid. Flywheels with large capacity around 10MJ can be implemented in the power grid, which results in the increase of the network quality. This system is able to stabilize voltage in the power grid with minimal tolerance for more than 10 minutes.

- High-power-UPS device. By combining several tens of flywheel batteries, a highpower-UPS device can be built. Delivery of a sufficient amount of energy for experiments with plasma, acceleration of heavy materials and super-large UPS systems, represent potential examples. The maximum power of around 50MW can be delivered from the UPS devices for more than 10 seconds, with overall efficiency exceeding $90 \%$. Similar flywheels have been tested for city buses and rail vehicles with savings up to several tens of percent.

- Applications in aerospace industry. Flywheel battery can replace or complement the standard batteries in some applications in on-board systems which results in considerable savings in weight and total volume of battery systems.

\section{ENERGY STORAGE IN FLYWHEELS}

Advances in material technology, magnetic bearings and power electronics have led to successful applications of flywheels in a short-term storage of energy. Modern flywheels work with high power and thanks to the composite materials, the flywheels reach high angular speed with power density higher than is the power of chemical batteries. Exploiting magnetic bearings significantly reduces internal losses (Kamf, 2012). Since the accumulated energy is proportional to the square of the speed and only linearly to the flywheel mass, the highspeed flywheel rotation is essential for accumulating a large amount of energy.

The benefits of flywheel applications (Bolund et al., 2007) for energy accumulation stems from basic properties of the flywheels, namely from:

- High power density;

- High energy density;

- Capacity of being independent of the depth of discharge and the number of charging cycles;

- Simple measurability of a charge status, which is given simply by the angular speed of the flywheel;

- Very short charging period;

- Very low maintenance requirements during flywheel operation.

One of the most important advantages of flywheels is their ability to handle high-level power. This property is required for example in vehicles if a high power is needed during vehicle acceleration. On the contrary, if a traction electric engine is used in the generator mode as a brake, the braking of the vehicle generates a large amount of energy in a short time interval and the breaking energy can be accumulated in the flywheel battery. It is evident that in such regime, energy is used more efficiently, which results in reducing fuel consumption and thus also in reducing $\mathrm{CO}_{2}$ emissions.

In principle, flywheels store energy into a rotating mass. The amount of stored energy depends on the weight and rotation speed of the flywheel. The recent flywheel designs place the rotating mass into vacuum, where the friction losses during extremely high revolutions of the rotor are reduced. An electric engine, which stores kinetic energy in the flywheel, can work in the reverse mode as a generator in case that energy from the flywheel battery can be exploited. 
The main purpose of the flywheel battery is the short term energy accumulation in the flywheel rotor for its later usage. Not only the shape of the rotor is important for the amount of the accumulated energy, but it is also the material from which the rotor is constructed. These parameters have a restrictive effect on the maximum stored energy that can be accumulated in the flywheel. This limitation stems, in particular, from the strength of the materials and also from characteristics of bearings used.

Modern flywheels usually consist of aluminium core that is coated with high-strength composite material. The composite acts as the main energy accumulator in the flywheel and temporarily at high speeds ensures the stability of the rotor as a whole, particularly if the rotational speeds exceed the aluminium-core strength limits. On the other hand, orthotropy of the composite materials causes complications in the flywheel design. In addition, the properties of the composite materials largely depend on the orientation of the fibres.

\section{HIGH-SPEED FLYWHEEL BATTERY}

Due to the dependence of the amount of the stored energy in a rotating mass on the square of the angular velocity, the highest possible angular velocities of the rotor in the flywheel battery are required. However, high rotational speeds greatly increase technical demands on the material properties of the rotor, the bearings and, last but not least, also on decreasing of the additional resistance acting on the rotating flywheel.

The amount of kinetic energy of a rotating mass is described by the basic equation:

$$
E_{k}=\frac{1}{2} J \omega^{2}
$$

Moment of inertia $(\mathrm{J})$ depends strongly on a shape of the rotating mass and its weight. The principal shapes of steel rotors are full cylinders, for which the following equation is relevant:

$$
J=\frac{1}{2} m r^{2}=\frac{1}{2} \pi a \rho r^{4}
$$

where $r$ is radius, $a$ is length of cylinder, $m$ is weight and $\rho$ is cylinder density.

The hollow cylinder is another frequently used shape of the flywheel rotor, for which holds

$$
J=\frac{1}{4} m\left(r_{0}^{2}+r_{i}^{2}\right)=\frac{1}{4} \pi a \rho\left(r_{0}^{4}-r_{i}^{4}\right) .
$$

It is evident from the equations above that achieving the highest angular speeds is decisive for storing the maximum amount of energy in flywheels.

On the other hand, there are limitations resulting from the material strength $\sigma$. Materials with low density and high strength are optimal for constructing flywheels.

The maximum energy density with regard to flywheel volume and weight is

$$
e_{v}=K_{\sigma}, e_{m}=K_{\rho}^{\sigma}
$$

where $e_{v}$ and $e_{m}$ are specific kinetic energy per units of volume and mass, and $K$ is the shape coefficient, $\sigma$ is the maximum strength of the (rotor) flywheel, and $\rho$ is the density of the material. 
Taking into account plane stress and assuming the height of the disc is relative to its diameter, the shape coefficient $K$ can be specified for homogeneous isotropic material with Poisson number 0.3 according to Table 1 .

Table 1: Shape factor $K$ in dependence of rotor cross-section (Bolund et al., 2007).

\begin{tabular}{lll}
\hline Fly wheel geometry & Shape factor K \\
\hline Disc & 1.000 \\
Modified constant stress disc & 0.931 \\
Conical disc & 0.806 \\
Flat unpierced disc & 0.606 \\
Thin firm & 0.500 \\
Shaped bar & & 0.500 \\
Rim with web & & 0.400 \\
Single bar & & 0.333 \\
Flat pierced bar & & 0.305
\end{tabular}

Three-dimensional interaction of tension exists in a three-dimensional body. For a rotor designed from non-isotropic materials, such as that formed by fiber-reinforced composites, three-dimensional interaction of tension will represent the limiting factor for realistic dimensions of the flywheel. Taking into consideration the security aspects, the hollow cylinder, in which the three-dimensional effects are minimized, is the basic shape. The radial and axial tensions dominate in the low-shape flywheels.

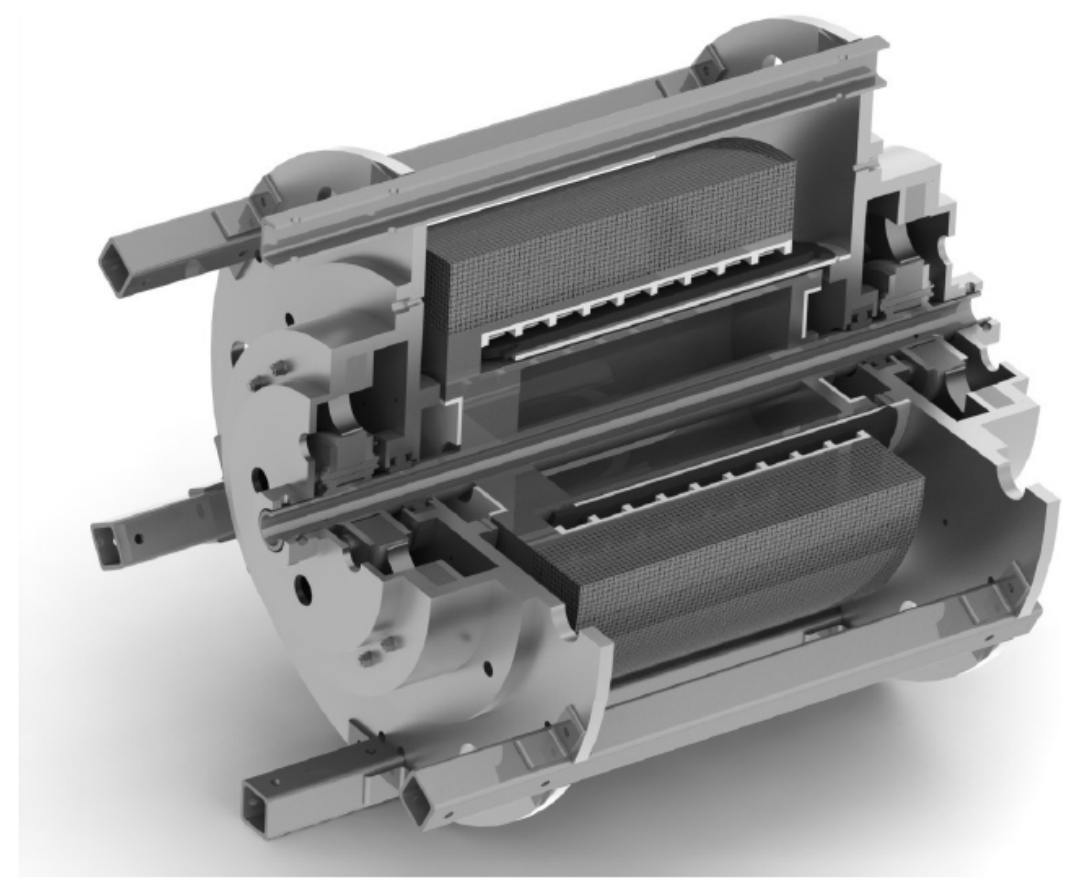

Figure 3: A cross-section of a potential high-speed flywheel battery design. 
From a technical point of view, there are no obstacles to design the high-speed flywheel battery (e.g. Tang et al., 2012). However, from an economic point of view, it is impossible to implement such designs into a serial production and apply them in a broad scale into common cars at present.

\section{NEW DESIGN OF ADDITIONAL FLYWHEEL BATTERY USING COMMONLY AVAILABLE COMPONENTS}

This paper aims to present a conceptual design of an efficient flywheel battery, designed with commercially available components. The design not only considers the flywheell rotor itself, but also its housing in a vehicle without additional extensive modifications. The basic idea is based on a possibility of using a spare wheel of a vehicle, or its steel or aluminium disc, as the gyroscope rotor at an early stage of rotor development.

We present an estimate of an amount of kinetic energy stored in a standard aluminium rotating disc, for which we consider technical parameters of the Crateris disc of Skoda Auto company, with diameter of $16 "$, mass $=9.73 \mathrm{~kg}$, and the moment of inertia $J=0.28 \mathrm{~kg} \cdot \mathrm{m}^{2}$. These parameters are suitable for tyres 205/55 R16, with dynamic radius of approximately $\mathrm{r}=0.3 \mathrm{~m}$. The aluminium disc is designed for maximum vehicle speeds, often exceeding $250 \mathrm{~km} / \mathrm{h}$. Speed (v) of the rotating disc, while the vehicle is moving, and its respective angular velocity, are linked according to the formula $v=\omega \times r$, where $\mathrm{r}$ is radius of the disc. The estimated values of angular velocities in dependence on a vehicle speed are presented in Table 2.

Table 2: Estimates of disc velocities.

\begin{tabular}{|c|c|c|c|c|c|c|c|c|c|}
\hline Vehicle speed $(\mathrm{km} / \mathrm{h})$ & 100 & 125 & 150 & 175 & 200 & 225 & 250 & 275 & 300 \\
\hline Angular velocity $(1 / \mathrm{s})$ & 92.6 & 115.7 & 138.9 & 162.0 & 185.2 & 208.3 & 231.5 & 254.6 & 277.8 \\
\hline Revolutions $(1 / \mathrm{min})$ & 884 & 1105 & 1326 & 1547 & 1768 & 1989 & 2210 & 2432 & 2653 \\
\hline
\end{tabular}

Wheel angular velocity, or speed of aluminium disc respectively, at high vehicle speeds are considerable high and hence a relatively large amount of energy can be stored in the rotating mass.

The amount of stored kinetic energy $E_{k}(J)$ can be calculated from the equation:

$$
E_{k}=\frac{1}{2} J \omega^{2}
$$

Where $J\left(\mathrm{~kg} \cdot \mathrm{m}^{2}\right)$ is moment of inertia and $\omega\left(\mathrm{rad} . \mathrm{s}^{-1}\right)$ is angular velocity of the rotating mass.

Similarly to Table 2 and based on the speed of rotation, we estimate the amount of the stored kinetic energy (Table 3).

Table 3: Estimates of amount of stored kinetic energy in kJ.

\begin{tabular}{|c|c|c|c|c|c|c|c|c|c|}
\hline $\begin{array}{c}\text { Angular velocity } \\
(1 / \mathrm{s})\end{array}$ & 92.6 & 115.7 & 138.9 & 162.0 & 185.2 & 208.3 & 231.5 & 254.6 & 277.8 \\
\hline $\begin{array}{c}\text { Angular velocity } \\
\text { (rad/s) }\end{array}$ & 582 & 727 & 873 & 1018 & 1164 & 1309 & 1454 & 1600 & 1745 \\
\hline Kinetic energy (kJ) & 47.4 & 74.0 & 106.6 & 145.1 & 189.5 & 239.9 & 296.2 & 358.3 & 426.5 \\
\hline
\end{tabular}


It is necessary to use the angular velocity $\omega$ for the equation of kinetic energy ( $\mathrm{J}$ ) in the units $\mathrm{rad} . \mathrm{s}^{-1}$. The angular velocity can be recalculated according to the formula rad. $s^{-1}=\frac{\pi}{180} \times s^{-1} \times 360^{\circ}$.

Table 4: Estimates of amount of stored kinetic energy in Wh, kWmin and $\mathrm{kW10sec}$.

\begin{tabular}{|c|c|c|c|c|c|c|c|c|c|}
\hline $\begin{array}{c}\text { Disc revolutions } \\
(1 / \mathrm{min})\end{array}$ & 884 & 1105 & 1326 & 1547 & 1768 & 1989 & 2210 & 2432 & 2653 \\
\hline Kinetic energy (kJ) & 47.4 & 74.0 & 106.6 & 145.1 & 189.5 & 239.9 & 296.2 & 358.3 & 426.5 \\
\hline Kinetic energy (Wh) & 13.2 & 20.6 & 29.6 & 40.3 & 52.6 & 66.6 & 82.3 & 99.5 & 118.5 \\
\hline $\begin{array}{c}\text { Kinetic energy } \\
\text { (kWmin) }\end{array}$ & 0.8 & 1.2 & 1.8 & 2.4 & 3.2 & 4.0 & 4.9 & 6.0 & 7.1 \\
\hline $\begin{array}{c}\text { Kinetic energy } \\
\text { (kW10sec) }\end{array}$ & 4.7 & 7.4 & 10.7 & 14.5 & 19.0 & 24.0 & 29.6 & 35.8 & 42.6 \\
\hline
\end{tabular}

It is evident from the calculated values of kinetic energy that the accumulated amount of energy is sufficient for an acceleration of a vehicle to approximately $50 \mathrm{~km} / \mathrm{h}$ solely by exploiting the accumulated energy. This becomes important particularly in urban areas. However, the main benefit of this flywheel battery is its ability to support the combustion engine in situations requiring a sudden high power supply from the combustion engine. Thus in such model modes, the combustion engine can run in economical mode and the flywheel can be used for a short-term demand of increased power for the vehicle acceleration.

The flywheel battery has been applied in the Formula 1 championship, which is often regarded as a pioneer of innovative technologies. However, the innovations used originally in the Formula 1 were at that time very expensive for serial production. From technical point of view, the efficiency of the innovations was proved and later such innovative batteries were incorporated into common cars. Thanks to large production, the cost of the battery production could be significantly reduced.

The flywheel battery in the Formula 1, known as system KERS (Kinetic Energy Recovery System), allowed maximum power of $60 \mathrm{~kW}$ for 6.67 seconds in the racing season 2009. The weight of the rotor of $5 \mathrm{~kg}$, revolution speed up to $60000 \mathrm{1} / \mathrm{min}$ and the accumulated energy resulted in approximately $110 \mathrm{Wh}$. Total weight of system KERS was $24 \mathrm{~kg}$. The accumulated energy in the presented design of the additional flywheel battery with the use of the aluminium disc is comparable with the energy stored in system KERS. Unlike in the Formula 1, a small increase in common vehicle weight, due to adding the battery comprising the rotor, does not mean any obstacle for common cars.

Particular design of an additional flywheel battery will depend on vehicle specifications. Fixing the rotor flywheel in a vehicle, which can be in the simplest case the aluminium disc, is assumed to be identical to the fixing used for mounting wheels on vehicle. Therefore, using of standard holes and screws is expected. The disc itself will be fixed to the flange of the rotor of the electric engine. The choice of electric engine, of a standard production on the market, depends on parameters of the flywheel battery. Speed up to $50001 / \mathrm{min}$ and storage of the short-term maximum power up to $40 \mathrm{~kW}$ for a few seconds are assumed which are commonly used in hybrid transmissions (ZF 8P automatic transmission).

To store the energy in a flywheel battery for several minutes, it is necessary to eliminate losses, due to an air resistance acting during the high-speed disc rotation. This can be effectively achieved by placing the flywheel battery in an airtight vacuumed container. Then, the resistive forces are significantly reduced and energy storage in the flywheel battery will be very effective. 
The design assumes the flywheel battery could be also connected to a standard $230 \mathrm{~V}$ outlet. Such configuration allows a quick recovery charging of the flywheel battery with a smaller amount of energy. The charging will be sufficient to start the combustion engine in case that the main vehicle battery operating at voltage of $12 \mathrm{~V}$ would not have sufficient amount of energy. Moreover, disconnecting of the standard $12 \mathrm{~V}$ main battery in dependence on the current situation is assumed. The energy required for the on-board vehicle systems will be delivered solely from the flywheel battery that increases the lifetime of a standard main $12 \mathrm{~V}$ battery in the vehicle.

An alternative to the above described conceptual design of the flywheel battery using the common aluminium disc could be its replacement with a high-strength steel disc, whose shape is optimized for the maximum strength. Other components of the flywheel battery, e.g. the electric engine, can be used without a change, providing the electric engine will allow higher speeds of the high-strength steel-disc rotor.

\section{CONCLUSION}

Significant requirements concern balancing of any rotating mass, including the rotor of a flywheel battery. Even small imprecisions in the mass balancing can cause additional forces acting on rotor bearings, causing vibrations and, in extreme cases, even a failure of the entire system.

Therefore, attention has to be paid to a correct balancing of the flywheel rotor. It is quite logical to exploit the same system of balancing for the rotating aluminium disc, which is used in the complete vehicle wheels. The small stick-on counter-weights can be added to peripheral parts of the aluminium disc. This commonly used technique is sufficient for the additional flywheel battery designed in Chapter 5 .

There are also other possibilities of rotor balancing, which are less common. Spontaneous balancing balls (granule powder) rotating together with the flywheel rotor on its inner side can be used as an example. This method, in which polymer granulates were applied into truck tyres, was invented in the 1990s in the USA. By this method, driving properties improved and tyre wearing was reduced into area of its contact with a road. Later, other balancing techniques, based on powder, derived from silica sand, porcelain and small glass balls, were invented. The principles of this kind of balancing are simple. Uneven radial forces act during the rotation of a tyre. Small balls permanently move to places with the lowest radial forces and thus balance differences among them. Usage of the same granule-powder trucktyre balancing system is also convenient for balancing the flywheel battery. The amount of the granule powder must be adjusted according to the weight of a flywheel rotor. Another possibility is to use small steel spheres with a diameter of approximately $6 \mathrm{~mm}$ for selfbalancing.

The presented new design of the additional flywheel battery, constructed predominantly from commonly available components of vehicles, shows a promising technical solution of an additional energy-storage system for common vehicles, which are usually equipped with a spare wheel. At present, cars become frequently equipped with adhesive sets to repair tyres after a puncture, instead of having a spare wheel. Thus the space for the spare wheel, usually under the luggage space, remains unused. Therefore, using this space for the proposed additional flywheel battery is a challenge. Moreover, the presented new design does not require any demanding specific development, including e.g. a production of a carbon-fibre rotor. In general, high-tech development would increase several times the rotational speed and the amount of stored energy, but from the economic point of view, such solution would have limitations in its wider distribution. Modern trends in technologies emphasize reducing both energy demands, as well as decreasing emissions from the means 
of transport. Therefore, the designed flywheel battery may be a new perspective short-term energy storage system. Extensive expansion of such flywheel battery does not seem to be limited by any major technological or economic barriers.

\section{REFERENCES}

Bolund, B., Bernhoff, H., Leijon, M., 2007. Flywheel energy and power storage systems. Renewable and Sustainable Energy Reviews, 11 (2), pp. 238-258.

Kamf, T., 2012. High speed flywheel design. Examensarbete 30 hp, TVE-12052. Uppsala Universitet.

Lee, J., Jeong, S., Han, Y. H., Park, B. J., 2011. Concept of Cold Energy Storage for Superconducting Flywheel Energy Storage System. IEEE Transactions on applied superconductivity, 21 (3), pp. 2221-2224.

Meeker, N., Walker, B., 2010. Flywheel Technology for Energy Storage.

Plomer, J., 2010. Setrvačník, inovativní řešení pro hybridní a elektrická vozidla, 1. díl. Hybrid.cz [online]. [cited 2014-05-26]. ISSN 1802-5323. Retrieved from: http://www.hybrid.cz/clanky/setrvacnik-inovativni-reseni-pro-hybridni-elektrickavozidla-1-dil (in Czech)

Plomer, J., 2011. Setrvačník, inovativní řešení pro hybridní a elektrická vozidla, 2. díl. Hybrid.cz [online]. [cited 2014-05-26]. ISSN 1802-5323. Retrieved from: http://www.hybrid.cz/clanky/setrvacnik-inovativni-reseni-pro-hybridni-elektrickavozidla-2-dil (in Czech)

Plomer, J., 2013. Hybridantrieb für ein Kraftfahrzeug [online]. ZF Friedrichshafen AG [DE]. Patent DE102011085149A1 [cited 2014-05-26]. Retrieved from: https://depatisnet.dpma.de/DepatisNet/depatisnet?action=bibdat\&docid=DE102011085149A1

Tang, Ch.-L., Dai, X.-J., Zhang, X.-Z., Jiang, L., 2012. Rotor dynamics analysis and experiment study of the flywheel spin test system. Journal of Mechanical Science and Technology, 26 (9), pp. 2669-2677.

Yang, X., 2012. Experimental research of a flywheel hybrid vehicle. In Chen, W.Z., Dai, P., Chen, Y., L.,Wang, Q., Jiang, Z. (eds.). Advanced mechanical design, PTS1-3, Advanced Material Research, (479-481), pp. 439-442. doi: 10.4028/www.scientific.net/AMR.479481.439. 